\title{
Standing-on-Shoulder and Fishing-Out Synergies: A Model for Endogenous Long-Waves
}

\author{
Grigoris Zarotiadis, Eirini Ozouni* \\ Division of Development and Planning, Department of Economics, School of Economics and Political Sciences, \\ Aristotle University of Thessaloniki, Thessaloniki, Greece \\ Email: gzarotia@econ.auth.gr, *ozouni@econ.auth.gr
}

How to cite this paper: Zarotiadis, G. and Ozouni, E. (2017) Standing-on-Shoulder and Fishing-Out Synergies: A Model for Endogenous Long-Waves. Theoretical Economics Letters, 7, 2194-2212.

https://doi.org/10.4236/tel.2017.77150

Received: September 20, 2017

Accepted: December 12, 2017

Published: December 15, 2017

Copyright $\odot 2017$ by authors and Scientific Research Publishing Inc. This work is licensed under the Creative Commons Attribution International License (CC BY 4.0).

http://creativecommons.org/licenses/by/4.0/

\section{c) (i) Open Access}

\begin{abstract}
Standard growth theory considers a constant, endogenously defined rate of technological change that generates a log-linear evolution of economic activity. Yet, the persistent current phase of worldwide slowdown triggers the awakening of "long waves" theories. In the present paper, starting from a dynamically evolving synergy of Romer's "fishing out" and "standing on shoulders" effects, we end up having three mechanisms that provoke a cyclical evolution of applied ideas: a direct impact through applied research's productivity; an effect through researcher's effort allocation; and an effect through the allocation of labour force. Putting these together, we initiate long waves of per capita (p.c.) output.
\end{abstract}

\section{Keywords}

Long Waves, Standing on Shoulders, Fishing out, Technological Change

\section{Introduction}

Neoclassical growth theory prophesizes a log-linear evolution of per capita income. It considers short path deflections as the stochastic result of common business cycles, while longer lasting fluctuations are perceived as the adjustment period towards a new balanced growth path, following any significant structural transformations. On the other hand, "long waves" tradition emphasizes the long-term cyclical variations over the history of capitalism's development and the reoccurrence of periods of amplified downturns. ${ }^{1}$ This approach is neglected by the stan-

${ }^{1}$ The first contributions appeared at the end of $19^{\text {th }}$ century by Jevons [1], Parvus [2], Van Gelderen [3], De Wolff [4] and the following, statistically more advanced, analysis of Kondratieff ([5] [6] [7]). 
dard theory, not so much due to any statistical rejection ${ }^{2}$ but mainly because it lagged of theoretical underpinning.

Traditionally, the occurrence of persistent long-lasting recessions triggers both the empirical but also the theoretical search for pro-"long-waves" arguments. Similarly to the 1930's and 1970's, the present persistent downturn gave also rise to a vigorous discussion: which could be the driving forces and are these fluctuations sequentially reappearing? With respect to the first question, historically, contributions can be categorised in three different schools: Marxists interpret long waves by the downward trend of the rate of profit, the indisputable driving force of the system. Nevertheless, the underlying process has not (yet) been convincingly introduced in the standard literature. Mandel [23] [24] [25] incorporated dialectically various exogenous factors-wars, geographical/sectoral market expansion and also technological revolutions-that counteract the systemic downward and move the economy back to a new phase of expansion. Closely to this, the Social Structure of Accumulation (SSA) School provides a theory of cyclical movements, where social institutional arrangements reassure the transition to the next upswing (Gordon [26] [27]; Gordon [28]; Gordon et al. [29]). Finally, the Schumpeterian/ Innovation School stresses out the cyclical movement of technological progress. Based on appropriate micro-oriented arguments, theorists consider the fluctuations of economic activity as the result of innovation-clusters (Kleinknecht [15] [30]; Mensch [31]; Schumpeter [32]). ${ }^{3}$

The second question about the sequential reappearance remains open too. Starting from the neo-classical tradition of Romer [48] and Aghion and Howitt [49], theorists focus on the slow adjustment to the new applications in order to model the re-emergence of "long waves" (Helpman \& Trajtenberg [50] and Aghion \& Howitt [51]. Yet, thereby they introduce an initially inverse effect of technology. Trying to avoid this shortcoming, more recent contributions, stepping on Kuhn's [52] shoulders, discriminate innovations between "basic" (or "fundamental" or "drastic" or "radical) and "incremental" (or "second${ }^{2}$ Despite the fact that "the longer a cycle, the harder it is to prove its existence" pointed out by Van Duijn [8], next to the studies that question the existence of long waves (Garvy [9]; Van der Zwan [10]; Van Ewijk [11], [12]; Solomou [13], [14]), there is a number of empirical confirmations using modern econometric techniques (Kleinknecht [15]; Kleinknecht and Bieshaar [16]; Korotayev and Tsirel [17]; Reijnders [18], [19]; Van Duijn [8], [20]; Metz [21]). Traditionally, researchers use decomposition methods, while more recently we find spectral and cross-spectral analyses, where the impact of more than one kind of cycles could be investigated simultaneously. A more detailed analysis of these methods is far beyond the scope of this paper-for more information see the discussion made of Reijnders [18] and the more recent one of Metz [22].

${ }^{3}$ In the course of time, various theoretical contributions combined the arguments of the mentioned schools, in order to avoid a mono-causal interpretation of long waves. Kleincknecht [33] encourages this mixture; neo-Schumpeterians include also SSA-arguments in their discussion (Clark et al. [34]; Freeman [35]; Perez [36] [37] [38] [39] [40]; Tylecote [41]), while other theorists combine the scarcity of natural resources with the emergence of new technologies (Rostow [42]; Volland [43]). Also Van Duijn ([8] [20]) incorporates Schumpeter's theory of innovation and the dynamic system of Forrester [44] and Sterman ([45] [46]) in his product life cycle approach. Influenced by post-Keynesian theory and Schumpeter's innovation theory [32], Minsky [47] is trying to justify inherently the existence of longer period economic cycles through the financial instability hypothesis (FIH). 
ary"). ${ }^{4}$ Most of these models associate the emergence of a new paradigm with the reallocation of researchers between the two different kinds of research, basic and applied, driven solely by the expected economic benefits. Long waves result from the exhaustion of economic opportunities (Van Zon et al. [57]; Yetkiner et al. [58]) and not from the cyclical evolution of knowledge itself, as this is the case in the modern Anglo-Saxon epistemology. On the other hand, Li [59] and Olsson [56], although they simulate a discontinuous evolution of technological paradigms, they end up having a growth rate of knowledge that evolves through jumps instead of smoothed cycles.

In the present paper, we discuss a framework that carries forward the described theoretical discussion. Setting a continuous synergy of the two contradictory effects of the existing stock of knowledge, initially introduced by Romer [48] - "Standing on Shoulders" (SoS) and "Fishing out" effect (FO) - enables us to model a cyclical evolution of knowledge itself, despite the socioeconomic circumstances, as described by Kuhn [52] and Mensch [31]. Moreover, following Sanders' [60] suggestion, this cyclical evolution depends also on each researcher's scientific motivation, driven by liking to reputation, which led us to introduce an alternative utility function. Thereby, we present an endogenous explanation of long waves using both, epistemological and micro-economic foundation. The synergy of SoS and FO generates three co-existing mechanisms, leading to a cyclical evolution path of bounded applied knowledge: a direct impact on the productivity of applied research, and two indirect; on the one hand through the decision whether to work in $\mathrm{R} \& \mathrm{D}$ sector or in production (allocation of labour force), while on the other through the allocation of researchers' efforts between basic and applied research.

The remainder of the paper is structured as follows: Section 2 sets up a detailed analysis of the model as a whole. In Section 3 we simulate the development of economic activity and we proceed with some indicative comparative statics. Finally, in Section 4, we summarize out and make some concluding remarks about the possible directions of future research efforts.

\section{Theoretical Model}

Almost all of the relevant literature, both in orthodox log-linear approaches and in heterodox analysis of cyclical trends, technological progress is recognised as the dominant driving force. In the present paper, as SoS and FO affect simultaneously the effectiveness of research, the evolution of applied knowledge itself follows a longer lasting cyclical path.

The following model relates strongly to the one initially presented by Romer [48] and later by Jones ([61] [62]). We hypothesize an economy with three sectors: the final good sector $(Y)$ with perfectly competitive producers, the intermediate capital-goods sector $(x)$ that consists of a number of monopolistic firms (Aghion and Howitt [51]; Jovanovic and Rob [53]; Olsson [54] [55] [56]; Van Zon et al. [57]; Yetkiner et al. [58]). 
and finally the research sector $(R)$ engaged in both, applied and basic research.

\subsection{Final Goods Sector (Y)}

The final goods sector $(Y)$ consists of perfectly competitive firms that produce final goods using capital goods and workers. Labour $(L)$ evolves log-linearly with an exogenous, constant growth rate $n$. Production in the final goods sector requires labour input $L_{Y}$ and capital goods $X_{p}$ where $i \in\left[0, A_{t}\right]$ and $A_{t}$ is the number of currently existing applicable ideas:

$$
Y=L_{Y}^{(1-a)} \int_{0}^{A} x_{i}^{a} \mathrm{~d} i
$$

Profit-maximization ${ }^{5}$ implies that each firm employs labour until its marginal product equals to wage $\left(w_{Y}\right)$ and capital until the value of its marginal product equals to its rental prize $p_{i}$. Therefore:

$$
\begin{gathered}
w_{Y}=(1-a) \frac{Y}{L_{Y}} \\
p_{i}(x)=a L_{Y}^{(1-a)} x_{i}^{(a-1)}
\end{gathered}
$$

Equations (2) and (3) are the inverse demand functions, and $\alpha-1$ is the inverse price elasticity of the demand for capital goods:

$$
\frac{\mathrm{d} p_{i}(x)}{\mathrm{d} x_{i}} \frac{x_{i}}{p_{i}(x)}=\frac{(a-1) a L_{Y}^{(1-a)} x_{i}^{(a-2)} x_{i}}{a L_{Y}^{(1-a)} x_{i}^{(a-1)}}=a-1
$$

\subsection{Intermediate Capital-Goods Sector $(x)$}

Before we proceed, let us, further assume for simplicity's sake that all capital goods are homogenous with respect to their usage in producing the final good. As a consequence, production function in Y-sector can be written as follows:

$$
Y=L_{Y}^{(1-a)} \int_{0}^{A} x_{i}^{a} \mathrm{~d} i=L_{Y}^{(1-a)} A x^{a}=\left(A L_{Y}\right)^{(1-a)}(A x)^{a}
$$

Also, the economy's total capital would be:

$$
\int_{0}^{A} x_{i}^{a}=A x=K
$$

With respect to the production of intermediate capital goods, $\mathrm{x}$-sector consists of monopolistic firms that acquire the patents (existing applicable ideas) from $\mathrm{R}$-sector and, based on those, transform one unit of capital into one unit of any of $X_{i}\left(x A_{t}=K_{t}\right){ }^{6}$ Profit $(\pi)$ maximization yields for each monopolistic firm the same optimal mark-up price $p_{x}\left(=p_{i}\right)$ over the constant marginal costs of producing any $X_{p}$ that is the interest for using one unit of capital $(r)$ :

$$
\frac{\mathrm{d} \pi}{\mathrm{d} x}=p_{x}^{\prime} x+p_{x}-r \stackrel{\left(\times \frac{1}{p_{x}}\right)}{=} \frac{p_{x}^{\prime}}{p_{x}} x+1-\frac{r}{p_{x}}=0 \Rightarrow p_{x} \stackrel{(4)}{=} \frac{r}{1+\frac{p_{x}^{\prime}}{p_{x}} x}=\frac{r}{a}
$$

${ }^{5}$ The price of the final output $Y$ is normalised to unity.

${ }^{6}$ Capital goods are assumed to be homogenous also with respect to their own production. 
Following, we derive also the maximum profits for each monopolistic firm:

$$
\pi=p_{x} x-r x \stackrel{(3)}{=} a L_{Y}^{(1-a)} x^{a}-r x=a \frac{Y}{A}-r x=(1-a) a \frac{Y}{A}
$$

If we substitute (7) in (3) and we drop the $i$-subscripts we get the following two expressions:

$$
\begin{gathered}
p_{x}=a L_{y}^{(1-a)} x^{(a-1)}=\frac{a L_{y}^{(1-a)} x^{a}}{x}=\frac{\left(\times \frac{A}{A}\right)}{x}=\frac{a{ }^{(1-a)} L_{y}^{(1-a)} A^{a} x^{a}(5),(6)}{A x}=a \frac{Y}{K} \\
r=a p_{x}=a^{2} \frac{Y}{K}
\end{gathered}
$$

As production function in Y-sector is Cobb-Douglas, $(1-\alpha) Y$ is the part of income that belongs to the labourers and $\alpha Y$ the one that compensates the owners of capital goods. Part of this capital income, in particular $\alpha^{2} Y\left(=K p_{x}\right)$, goes to the owners of capital, while the rest, $\alpha(1-\alpha) Y$, is the sum of the retained income by the profit maximization of all monopolistic firms.

\subsection{Research Sector (R)}

As previously mentioned, $A_{t}$ is the stock of the applied ideas providing the necessary knowledge for producing different types of capital goods. Each new design is patent protected. The researcher that invents a new applied idea sells the patent to a firm producing intermediate capital goods.

Unlike to standard framework, we think of patents not being resalable and we model the market for patents in a simpler way: at each moment (or in each period) capital-goods producing firms invest all of their attained profits, $\alpha(1-\alpha) Y$, in order to buy the currently developed and supplied patents $(\mathrm{d} A / \mathrm{d} t)$, in their effort to, maintain/if not expand their monopoly power. Setting demand equal to supplied new applicable ideas obtains the equilibrium price for any new patent $p_{A}$, which then defines the nominal remuneration of researchers, $W_{R}{ }^{7} \mathrm{Al}-$ gebraic:

$$
\dot{A} p_{A}=\pi A \Rightarrow p_{A}=\frac{\pi}{g_{A}}
$$

where, $g_{A}$ is the growth rate of new applicable ideas.

As Romer suggests, on the one hand, the more we know the higher will be the productivity of the researcher ( $\mathrm{SoS})$; on the other, as our knowledge evolves, discovering new ideas becomes gradually harder (FO). The step forward we make is that instead of taking the magnitude of these effects as given through time, we anticipate that they change as the stock of knowledge grows and so does the combinational impact on the productivity of researchers. In the present model, we introduce the continuously changing synergy of these two theoretical arguments in the sense of a probability function. As $A$ grows, SoS amplifies the ${ }^{7}$ Notice that the sum of savings originated from the income of production workers, $s(1-\alpha) Y$, from researchers, $s w_{R} L_{R}=s \alpha(1-\alpha) Y$, and from capital owners, $s \alpha^{2} Y$, gives total savings for the economy, $s Y$. 
probability of discovering a new applicable idea $\left(P_{S A}\right)$. Then again, as $A$ grows towards the limits of the current Scientific Paradigm (SP) there is a negative effect on the same probability due to the worsening of FO $\left(P_{F}\right)$ :

$$
\begin{aligned}
& P_{S A}=\left(\frac{A_{t}-\tilde{A}_{c-1}}{\tilde{A}_{c}-\tilde{A}_{c-1}}\right)^{1 / u} \\
& P_{F}=\left(\frac{\tilde{A}_{c}-A_{t}}{\tilde{A}_{c}-\tilde{A}_{c-1}}\right)^{1 / m}
\end{aligned}
$$

where, $\tilde{A}_{c}$ is the limited set of detectable ideas under the current SP, $\tilde{A}_{c-1}$ the same for the previous SP and $u, m \in(0,1]$.

Putting both effects together, overall probability for being successful in applied research is simply the product $P_{S A} P_{F}$. In Figure 1 we show how $P_{S A} P_{F}$ first increases but then falls with increasing $A_{t,}$. Note that this is the "key" of the present model. Similar to the setting of Romer, marginal production of applicable ideas can be defined as follow:

$$
g_{A} \rightarrow \frac{\mathrm{d} A / \mathrm{d} t}{A}=\frac{P_{S A} P_{F}(1-b) L_{R}^{\lambda}}{A}, b \in(0,1)
$$

where $L_{R}$ is the number of researchers, $\lambda \in(0,1]$ refers to duplication effect and $(1-b)$ is the fraction of their time utilized for applied research (see the next pages).

Setting the first derivative of $P_{S A} P_{F}$ with respect to $A_{t}$ equal to zero provides the following condition for maximum probability:

$$
A_{t}=\frac{\tilde{A}_{1} m}{(m+u)}
$$

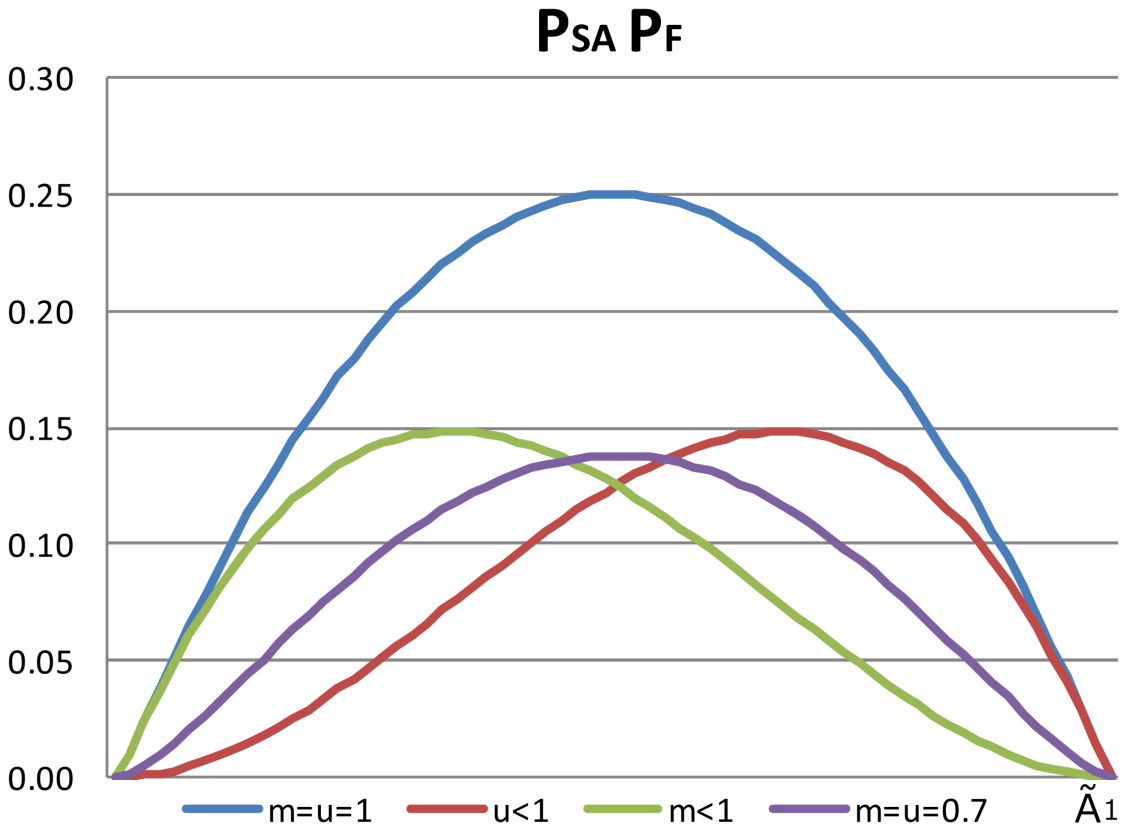

Figure 1. Probability of success in applied research (picture is drawn for $\tilde{A}_{c-1}=\tilde{A}_{0}=0$ ). 
Obviously, in case of $m=u$, the picture we get is symmetric (blue and purple curve). For lower $m$ and $u$, the curve moves downwards (purple curve). Moreover, if $m(u)$ becomes less than $u(m)$, the curve is positively (negatively) skewed due to the enhancement of FO (SoS).

Analogously, we can also describe basic research, namely the discovering of fundamental concepts forming the very basic scientific environment, where applied research takes place. For this type of research, only "standing on shoulders" argument is relevant. If we accept that there is no (or at least no evident) limit for human science in general terms, "fishing-out" does not apply for basic research:

$$
P_{S B}=\left(\frac{A_{t}}{\tilde{A}_{c}}\right)^{1 / u}
$$

(Note that $P_{S A}=P_{S B}$ for the first paradigm, where $\tilde{A}_{c-1}=0$ ).

Next, we determine effort allocation endogenously. ${ }^{8}$ The representative researcher divides her/his effort between basic (b) and applied research (1-b) in order to maximize her/his CES utility. This is simply a function of her/his nominal remuneration from selling the patented applicable ideas she/he developed $\left(w_{R}\right)$ and the reputation she/he expects to receive from basic research $\left(\Phi_{E}\right)$, as being one of the pioneers of human scientific heritage (Sander, 2007):

$$
U_{R}=\left(\gamma w_{R}^{\rho}+(1-\gamma) \Phi_{E}^{\rho}\right)^{\frac{1}{\rho}}, \rho \& \gamma \in(0,1)
$$

where $w_{R}$ can be defined as following:

$$
w_{R}=(1-b) p_{A} P_{S A} P_{F}
$$

and $\Phi_{E^{*}}$

$$
\Phi_{E}=\varepsilon \eta \Phi_{A}
$$

Equation (18) needs to be discussed in detail as it constitutes, along with the continuously changing synergy of SoS and FO, the main contribution of the presented framework. Expected reputation is simply the extent of attainable reputation $\left(\Phi_{A}\right)$ defined by the size of the new $(\mathrm{SP})^{9}$ multiplied by the probability ${ }^{8}$ Note that, up to this point, even without the specifications on effort between basic or applied research and labour allocation between Final and Research Sector, the cyclical evolution of our economy could be achieved only by the assumptions on the evolution of Applied Research. In that case, the cyclical economic evolution could be achieved by using a more simplified version of our model. However, then, the cycles would not have an endogenous theoretical underpinning. By including these specifications, the allocation of labor and effort influences each cycle's intensity and duration and most importantly, the model provides an endogenous mechanism that specifies the size of each scientific paradigm.

${ }^{9}$ For the purpose of the present analysis, we think of $\Phi_{A}$ as an exogenous parameter. Yet, the size of the scientific revolution (paradigm shift) is simply the distance between the new enhanced limit of applied ideas under the new paradigm $\left(\tilde{A}_{c+1}\right)$ minus the old set of ideas under current $\left(\tilde{A}_{c}\right)$. If we also assume for simplicity that one new applicable idea equals to one unity of reputation, $\Phi_{A}$ could be defined as follow: $\Phi_{A}=\int_{\tilde{A}_{c}}^{\tilde{A}_{c+1}-\tilde{A}_{c}} x_{i} d_{i}=\left(\tilde{A}_{c+1}-\tilde{A}_{c}\right) x$. Further expansion could be made by trying to estimate the size of this achievement. For example, we could assume that: $\left(\tilde{A}_{c+1}-\tilde{A}_{c}\right)=f\left(P_{S B}\right)=\left(\frac{1}{1-P_{S B}}\right)^{v}$. 
of the emergence of a paradigm shift $(\varepsilon)$ and the probability of being the one who gets the credits $(\eta)$.

The emergence of a new scientific paradigm is a result of a collective procedure including the effort oriented to basic research of all researchers, analogue to the situation in a store where the combination of activities of each salesman and staff member increases the probability of having a sale. It is a Poisson process with an arrival rate $\mathcal{E}$, which, in other words is the probability for having a new Paradigm Shift in the next moment (approximately now). We need $\varepsilon$ to be a function of the researcher's productivity of new basic ideas $\left(P_{S B}\right)$, his effort devoted to basic research $(b)$ and finally the amount of the researchers in our economy at each time $\left(L_{R}\right)$. If there is only one researcher, then the probability of a new SP shall be equal to $P_{S B}$ times $b$. On the other hand, in case the amount of the researchers goes to infinity then the probability tends to 1 and the emergence of the new paradigm appears to occur mainly due to the fact that the number of researchers increases. Thus:

$$
\varepsilon=\left(P_{S B} b\right)^{\frac{1}{L_{R}}}
$$

However, as in the example of a commercial store, a successful sale might be the result of collective effort, but the credit is given to the one that serves the customer. Similarly, in a research community, despite of the fact that all researchers contribute to the arrival of a paradigm shift, the credits will be given to the one that will make the final contribution and invent the new, revolutionary idea. The probability that a specific researcher will be the one that makes the final contribution $(\eta)$ must be positively related to $b$, negatively to $L_{R}$, varying from one to zero when $L_{R}$ is 1 or tends to infinity respectively. Thus:

$$
\eta=\frac{b^{\frac{L_{R}-1}{L_{R}}}}{L_{R}}
$$

If we substitute (17) (19) and (20) in (16) $)^{10}$ and set the first derivative of $U_{R}$ with respect to $b$ equal to zero, we get $b^{*}$ that maximizes researcher's utility:

$$
b^{*}=\left[\left(\frac{(1-\gamma)\left(\frac{P_{S B}^{\frac{1}{L_{R}}} \Phi_{A}}{L_{R}}\right)^{\rho}}{\gamma\left(p_{A} P_{S A} P_{F}\right)^{\rho}}\right]^{\frac{1}{\rho-1}}+1\right]^{-1}
$$

As expected, $b$ is related negatively to the "wage" parameters, $p_{A}, P_{S A}, P_{F}$ and positively to "reputation" parameters $\Phi_{A}$ and $P_{S B}$. Note that in case we are in the very first paradigm, the two SoS effects $\left(P_{S A}\right.$ and $\left.P_{S B}\right)$ are identical. ${ }^{11}$

${ }^{10}$ Note that multiplying $\varepsilon$ times $\eta$ simplifies the exponent of $b$ to one.

${ }^{11}$ Diachronically and within one Paradigm, $b$ is stabilized at a particular value. 
The definition of optimal allocation of research effort helps us to proceed with the endogenous allocation of working force $L$. Apparently, as individuals decide whether to work in Y- or $R$-sector, they compare the previously defined maximum attainable $U_{R}$ with the utility they can achieve by being a labourer, $U_{Y}=$ $\left(w_{Y}, 0\right)$, where expected reputation is simply zero. As more individuals decide to work in production (research), $U_{Y}\left(U_{R}\right)$ becomes lower (higher). So, the condition for an equilibrium allocation between workers $\left(L_{Y}\right)$ and researchers $\left(L_{R}\right)$ is simply $U_{Y}=U_{R}$ :

$$
\begin{aligned}
& U_{Y}=U_{R}\left(b^{*}\right) \Rightarrow\left(\gamma w_{Y}^{\rho}+(1-\gamma) 0^{\rho}\right)^{\frac{1}{\rho}}=U_{R}\left(b^{*}\right) \\
& \Rightarrow \gamma^{\frac{1}{\rho}} w_{Y}=U_{R}\left(b^{*}\right) \Rightarrow L_{Y}=\frac{\gamma^{\frac{1}{\rho}}(1-a) Y}{U_{R}\left(b^{*}\right)}
\end{aligned}
$$

and

$$
L_{R}^{*}=L-L_{Y}
$$

where, $L$ grows log-linearly with an exogenous growth rate $n$.

\subsection{The Three Mechanisms}

Recall Equation (13): the marginal change of the stock of applicable ideas depends on three arguments; the product $P_{S A} P_{F}$ the share of research effort devoted to applied research $(1-b)$ and of course the number of researchers $L_{R}$. The synergy of SoS and FO determines all these parameters. In other words, it provokes three mechanisms through which the growth rate of A and thereby of per capita income is being affected.

First, recall the direct effect, as the cyclical evolution of $P_{S A} P_{F}$ is being directly transferred to the productivity in applied research itself and thereby in $g_{A}$. Figure 2 depicts this: it simply simulates Equation (13) for given $b$ and an exponentially growing $L_{R}$ (constant $L_{R} / L$ ). The result is a cyclically evolving "engine of growth".

Moving on, there are two indirect impacts: SoS and FO affects the decision whether to do basic or applied research-see the definition of $b^{*}$ in Equation (21)-as well as each individual's choice to become a researcher or a production worker-recall Equation (22). The wage earned form applied research $\left(w_{R}\right)$ is a crucial parameter for both decisions-becoming a researcher or not and how much to be involved in applied research. Still, $w_{R}$ is simply the product of $p_{A}$ and $\mathrm{d} A / \mathrm{d} t$ (divided by $L_{R}$ ), which in turn is mainly affected by $P_{S A} P_{F}$ As we see in Figure 3 that depicts the results of an indicative simulation, after taking all three mechanisms together the cyclical evolution of $A$ remains, although the duration of the wave has been reduced.

\section{Long Waves of Economic Development}

In Section 2 we presented a theoretical framework that notably relates to the one initially presented by Romer [48] and later by Jones ([61] [62]). Yet, starting 


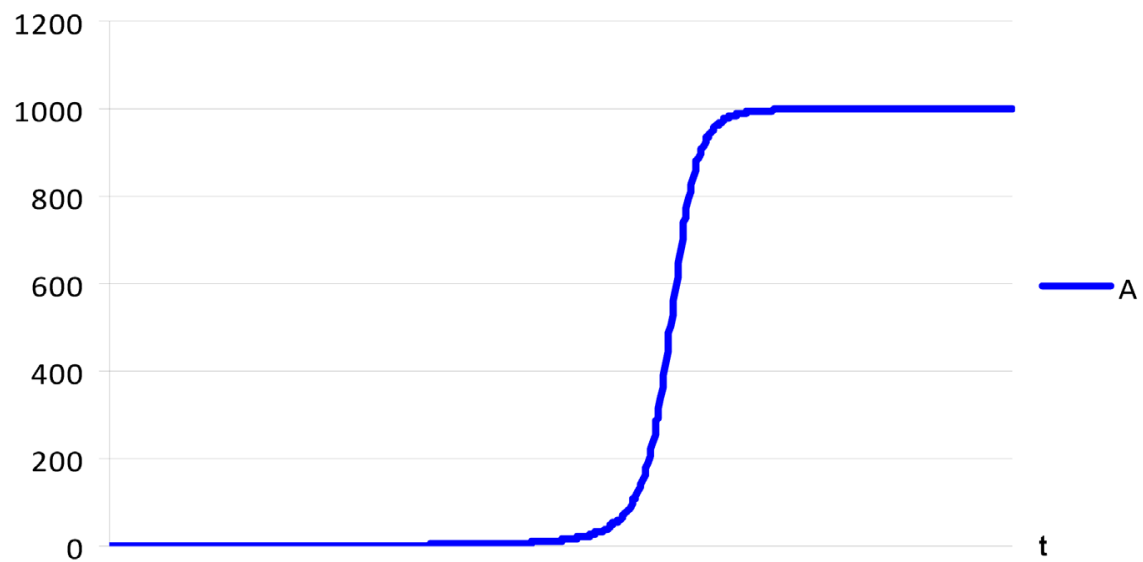

(a)

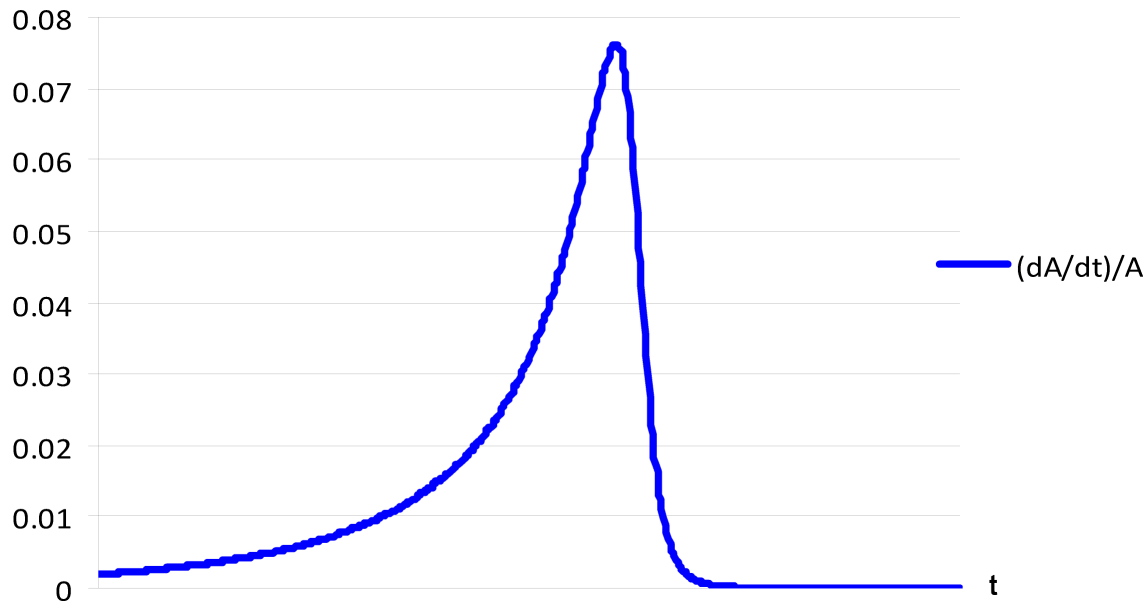

(b)

Figure 2. Evolution of $A$ within a scientific paradigm.

from the evolving synergy of SoS and FO, we set off three mechanisms inducing cyclicality in the evolution of applied ideas $(A)$ : the productivity in applied research itself; an effect through the allocation of researcher's effort; and finally, another one through the allocation of labour force in $L_{R}$ and $L_{Y \cdot}{ }^{12}$ Putting these together initiates long waves of per capita output $(y)$.

Standard literature recognises in technical change the engine of growth. Thereafter, having long-lasting cycles of $\mathrm{d} A / \mathrm{d} t$ allows us to reasonably deduce on the existence of endogenous long waves of per capita output $(y=Y / L)$. As the instability of labour force allocation prevents any analytical solution, we proceed with a sensitivity analysis, simulating the long waves, testing the robustness of the presented model and understanding how the exogenous socioeconomic characteristics affect the economy. (In the following figures, we depict the evolution of the growth rate of per capita income $g_{y}$ and that of the probability of having a paradigm shift, $\boldsymbol{\varepsilon}$.)

\footnotetext{
${ }^{12}$ As we saw, within a scientific paradigm, the endogenously defined share of labour force employed in R-sector $\left(\mathrm{L}_{\mathrm{R}} / \mathrm{L}\right)$ is non-stable and relates to the rest socioeconomic characteristics. This is also the reason for why the model cannot be solved analytically.
} 


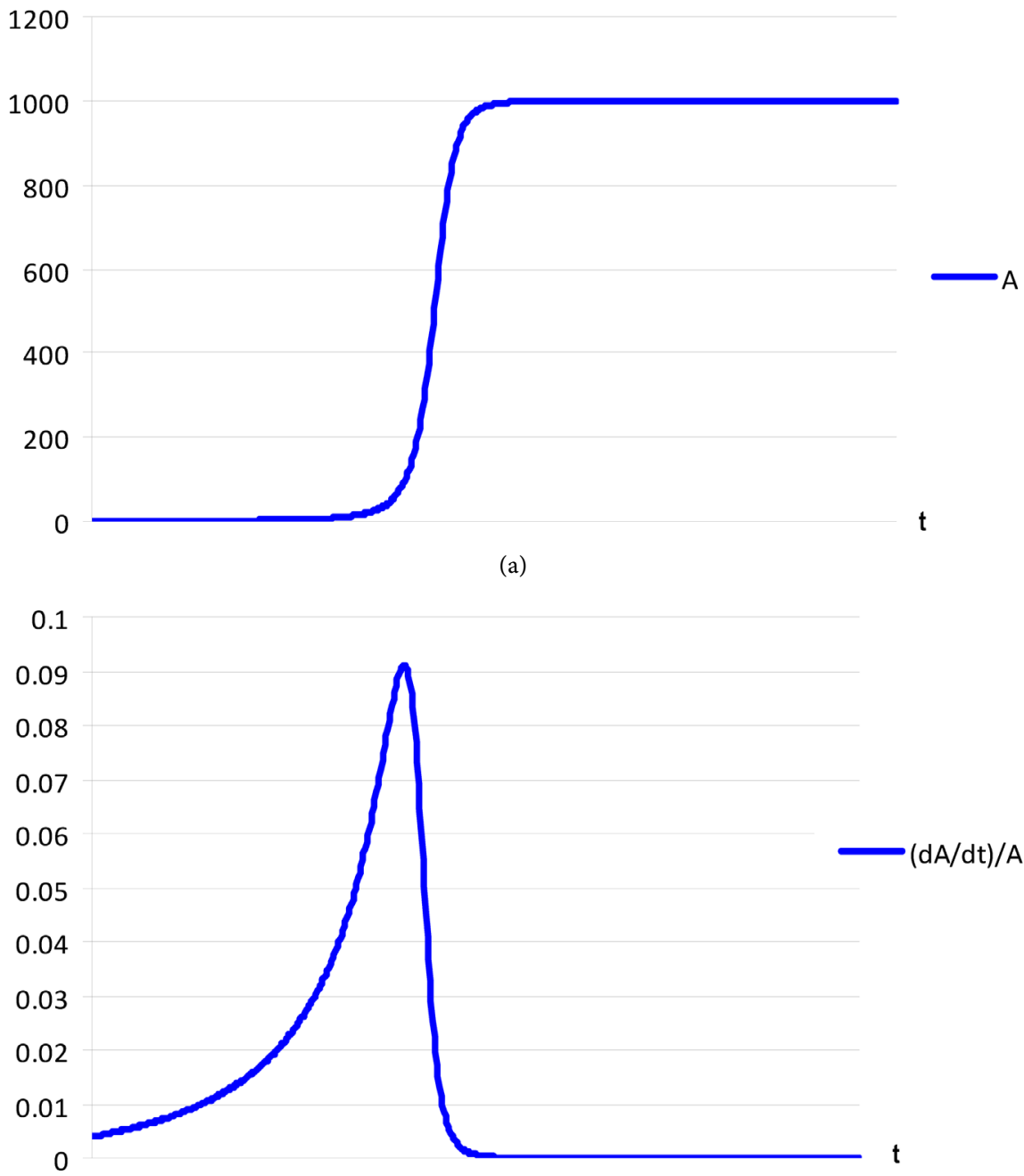

(b)

Figure 3. Evolution of $A$ and $g_{A}$ within a SP with endogenous $b$ and $L_{R}$.

Before we discuss the following simulations in detail, it will be useful to recall the main aspects of the presented framework. The described economy has three sectors: the final good sector $(Y)$ with perfectly competitive producers, the intermediate capital-goods sector $(x)$ consisting of monopolistic firms and finally the research sector $(R)$ engaged in both, applied and basic research. Labour $(L)$ evolves log-linearly with an exogenous, constant growth rate $n$. Each one decides whether to work in $\mathrm{Y}$ - or in $R$-sector, after comparing the utility she/he can achieve, $U_{Y}$ and $U_{R}$. Note that utility is made out of nominal remuneration and expected reputation: $U=U\left(w, \Phi_{E}\right)$. So, any researcher needs to take another decision too, namely how much to be engaged in applied and basic research. The first results into new patents that can be sold to x-sector, ensuring her/his nominal remuneration. The second gives rise to new, revolutionary knowledge, rewarding the researcher simply by the reputation that she/he could get, as being one of the pioneers of human scientific heritage. Given the current price of new patents and the expected reputation, representative researcher allocates appro- 
priately her/his effort to maximize attainable utility. This is apparently a crucial co-determinant of labour's division in Y- or in R-sector.

Production in the final goods sector employs $L_{Y}$ labour input and $x A_{t}$ homogenous capital goods, where $A_{t}$ is the number of currently existing applicable ideas. Final output is allocated to a share for the labourers, $(1-\alpha) Y$, and another that compensates capital goods $(\alpha Y)$. On the other hand, production function in $\mathrm{x}$-sector is even simpler: based on the acquired patents, monopolistic firms transform one unit of capital into one unit of any different type of capital good. Solving their profit maximization, the monopolistic firms obtain the optimal mark-up price $p_{x}$ and the constant marginal costs of producing $X_{p}$ namely the interest for using capital $(r)$. Thereby we decompose further $\alpha Y$ into $\alpha^{2} Y$, which is the amount of income that goes back to the capital owners, and $\alpha(1-\alpha) Y$ that refers to the sum of maximized profits attained by all monopolistic firms. At each moment (or in each period) capital-goods producing firms invest all of their attained profits, $\alpha(1-\alpha) Y$, in order to buy the currently developed and supplied patents $(\mathrm{d} A / \mathrm{d} t)$, in other words the outcome of applied research, where the dynamic synergy of SoS and FO modifies continuously the researchers' productivity. Clearing the patent market provides the equilibrium price for any new patent $p_{A}$, which then defines the nominal remuneration of researchers, $w_{R}$. Notice that the sum of savings originated from the income of production workers, $s(1-\alpha) Y$, from researchers, $s w_{R} L_{R}=s \alpha(1-\alpha) Y$, and from capital owners, $s \alpha^{2} Y$, gives total savings for the economy as a whole, $s Y$, which in turn counteracts depreciations and increases the capital stock.

Figure 4 depicts the first simulation, where we check for the effects of saving rate. As $s$ amplifies, capital accumulation is getting stronger, $Y$ is positively affected and thereby also $w_{Y}$, which implies further higher $L_{Y} / L$. This provokes a slightly longer upward phase pushing the peak to a later time, yet, the intensity is not changing (the peak of the wave remains the same). Analogously, the probability for having a new Paradigm Shift $(\mathcal{E})$ is being reduced in any moment. ${ }^{13}$

Quite similar is the picture we get when we let $\rho$ to take higher values (Figure 5 ), yet this time for different reasons. As $\rho$ increases, the structure of utility function changes and favours the attainable utility of researchers, in contrast to the utility of workers that depends solely on the received wage and remains unaffected by any change.

The next figure (Figure 6) illustrates the sensitivity analysis for raising capital's output elasticity $(\alpha)$. There are two effects: first, the intensity of the wave is being amplified. In other words, there is a clear positive effect on the growth rate $g_{y}$ during the expansion phase; second, as $\alpha$ increases the peak arises earlier meaning that the duration of expansion phase becomes shorter. In other words, the waves skews positively. The same is obvious in the second diagram, as probability for a paradigm shift is higher throughout the cycle.

${ }^{13}$ Logically, when we repeat the same analysis for the depreciation rate $d$, we get exactly the opposite picture. 


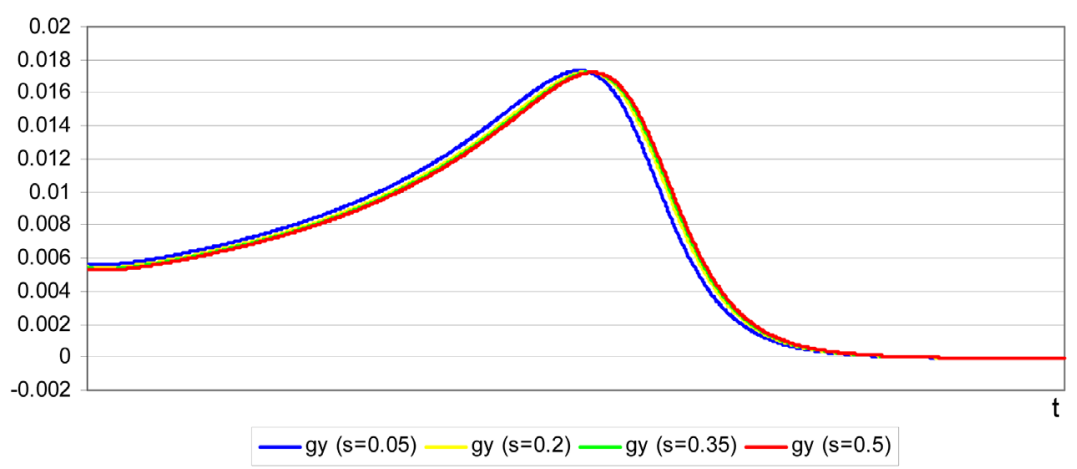

(a)

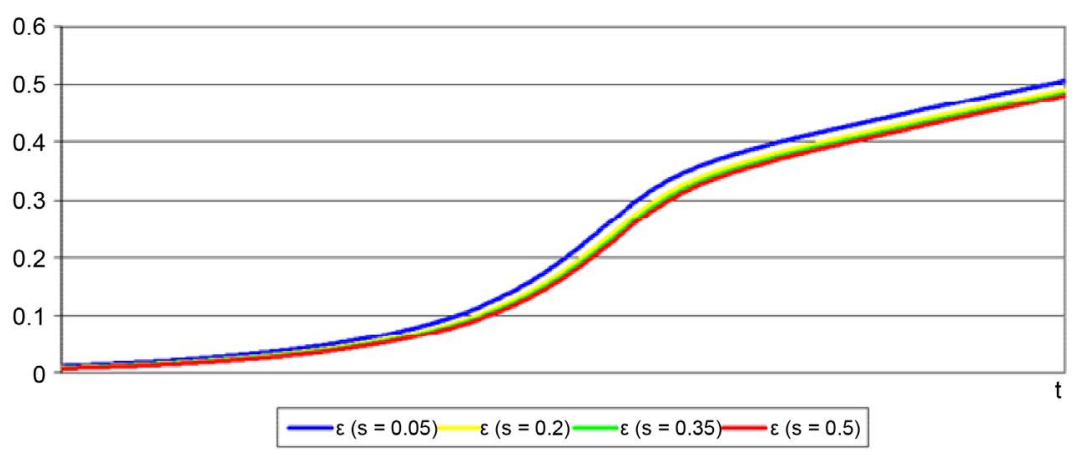

(b)

Figure 4. Evolution of $g_{y}$ and $\varepsilon$ within a SP, for different $s$.

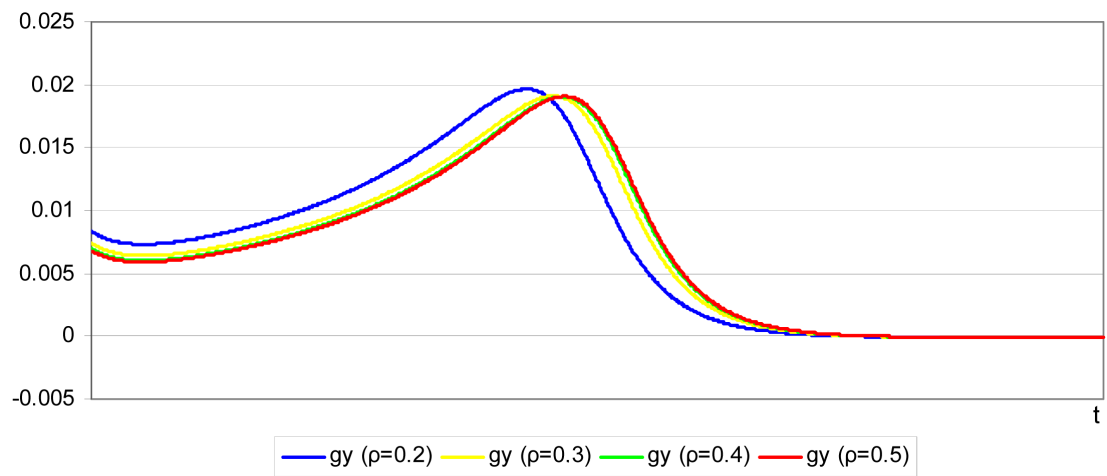

(a)

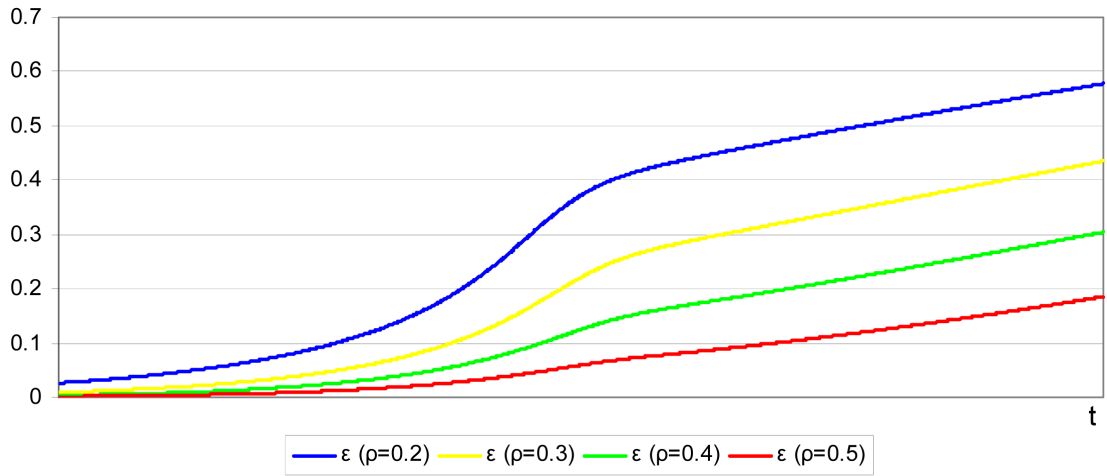

(b)

Figure 5. Evolution of $g_{y}$ and $\mathcal{E}$ within a SP, for different $\rho$. 


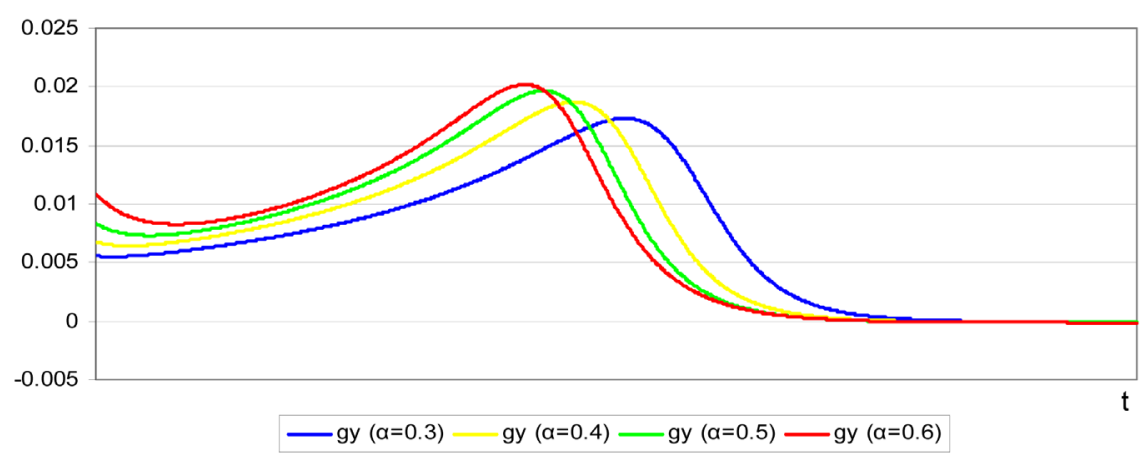

(a)

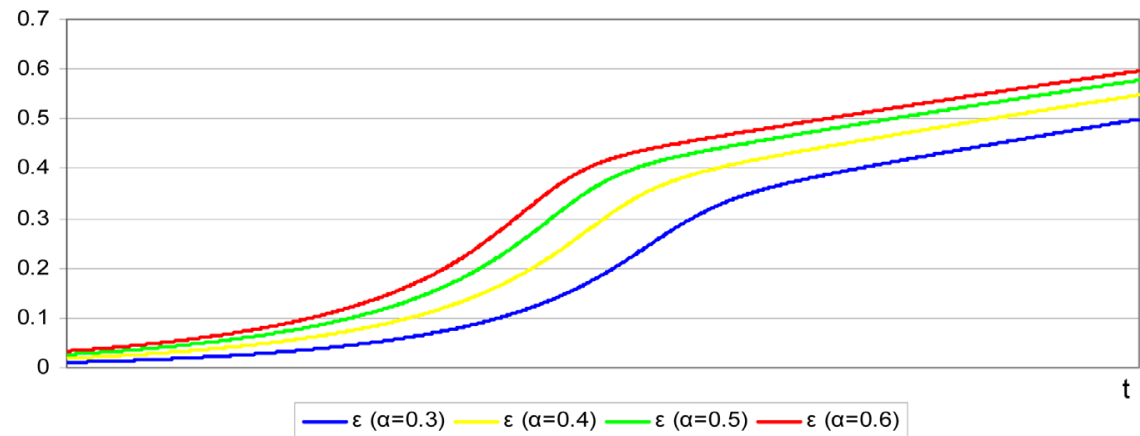

(b)

Figure 6. Evolution of $g_{y}$ and $\varepsilon$ within a SP, for different $\alpha$.

We move on to the impact of changes in $m$, the severity of FO-effect. The picture we get (Figure 7) confirms the previous discussion for the synergy of SoS and FO. Recall that for lower $m$, the curve depicting the evolution of overall productivity in applied research moves downwards and skews positively (Figure 1). This is exactly the case in $g_{y}$ : as $m$ decreases, the wave becomes smoother, while the peak moves leftwards and the duration of downturn phase increases. Obviously, for $u$, the intensity of SoS-effect, we get the opposite picture.

Finally, the effect of population's growth rate is similar to that of $\alpha$ (Figure 8). Namely, a slightly increasing $n$ generates shorter expansion phase and much more intense waves (higher peaks).

\section{Concluding Remarks}

In the previous paragraphs we discussed a theoretical framework that generates endogenous cyclical evolution of the applied knowledge and therefore of economic activity, similar to the tradition of long wave innovation theories. In a way, we combine standard arguments with Kuhn's tradition. Starting from a dynamically evolving synergy of Romer's FO and SoS effects, we end up having three mechanisms that provoke cyclicality in the evolution of applied ideas: a direct impact through the productivity in applied research itself; an effect through the allocation of researcher's effort; and finally, another one through the division of labour force in $L_{R}$ and $L_{Y}$. Putting these together initiates long waves of per capita output $(y)$. 


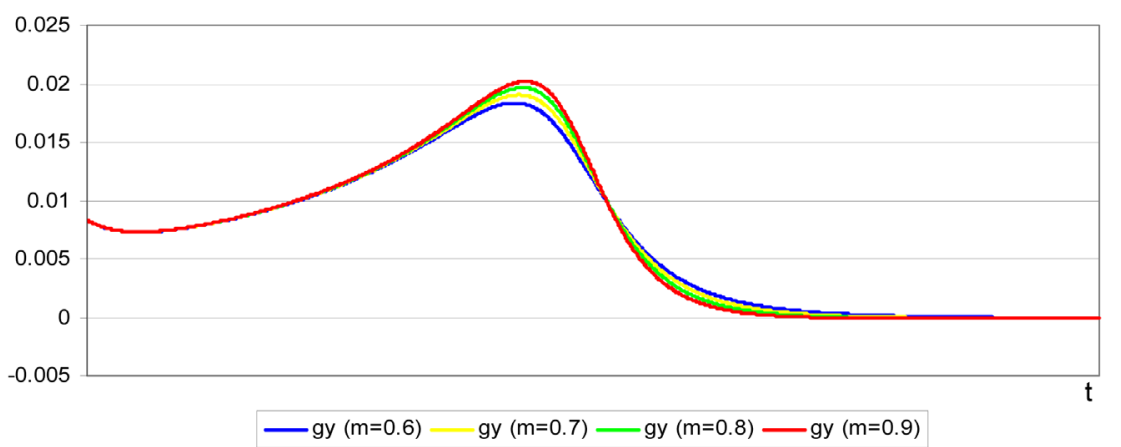

(a)

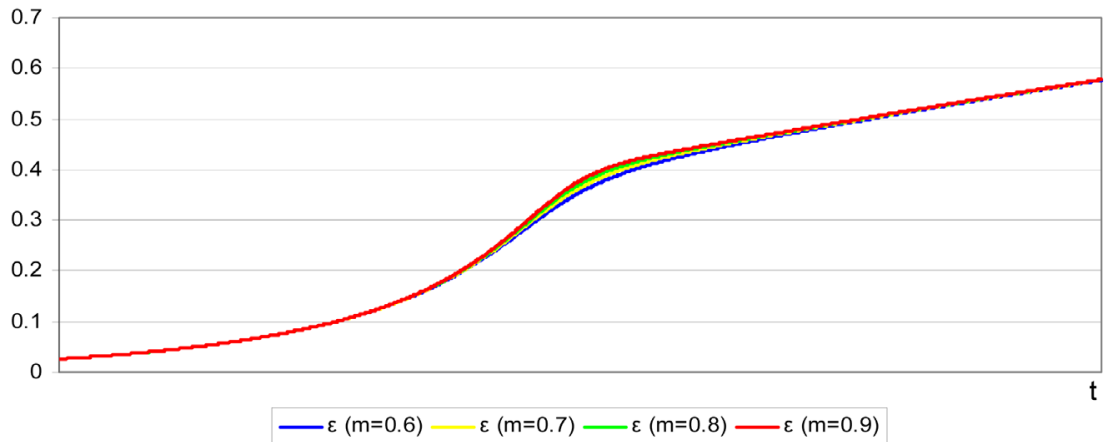

(b)

Figure 7. Evolution of $g_{y}$ and $\varepsilon$ within a SP, for different $m$.

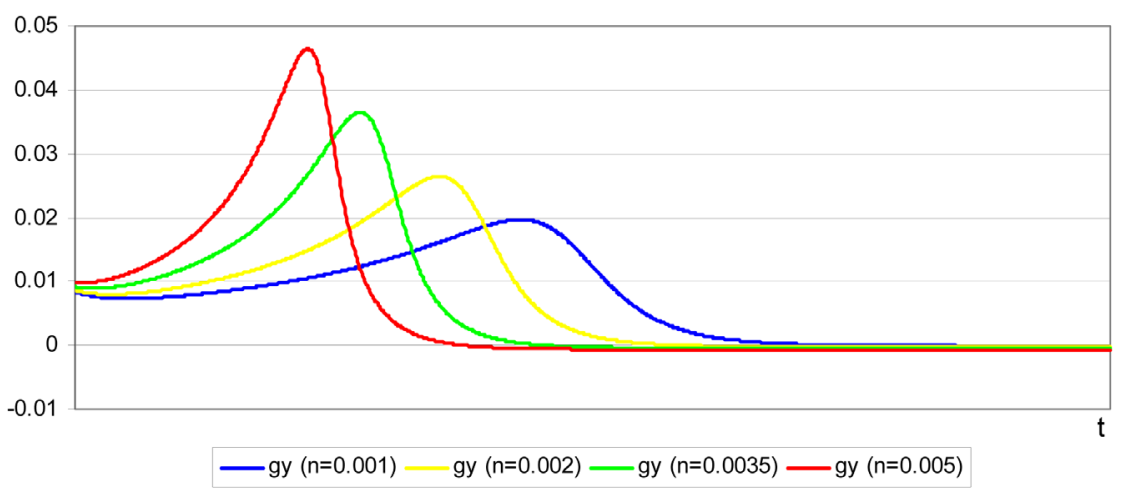

(a)

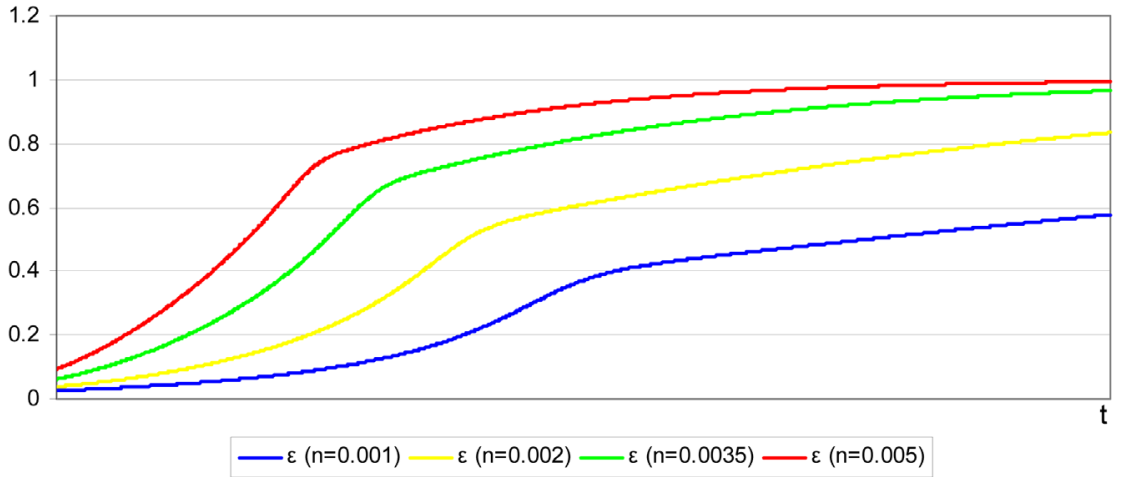

(b)

Figure 8. Evolution of $g_{y}$ and $\varepsilon$ within a SP, for different $n$. 
The presented analysis builds upon both epistemological and micro-economic foundation and, contrarily to other contributions, generates smoothly evolving cyclical movements. We incorporate our innovative arguments in a framework similar to the standard models of log-linear growth. Thereby, we enable direct comparisons and we provide a theoretical framework for analysing the effects of various socioeconomic parameters and policy interventions.

The previous pages provide a straightforward justification for the appearance of long waves. Besides, the model we propose explains the sequential character of waves in a more consistent way compared to the existing literature. Recall that as we approach the limits provided by the current scientific paradigm, $\varepsilon$ (the probability of having a new, path-breaking basic innovation) tends to one. Indeed, this paradigm shift will be stronger, the more delayed it will be. Notice again that this brings us back to the process described by Kuhn: as the basic knowledge of our society evolves, new areas of possible applications arise, waiting to be discovered. Nevertheless, as we exhaust the limited set of applications, given by the existing fundamental concepts (current Scientific Paradigm), anxiety accumulates gradually in the society. Sooner or later, this tension will be released, leading to new, revolutionary developments of our social knowledge, setting up a new period, where new, previously unthinkable applications can be developed. Moreover, the theoretical framework we present can be easily extended in order to determine endogenously the intensity of the new scientific revolution, as well as the probability of its occurrence in time, given the specific socioeconomic characteristics.

\section{References}

[1] Jevons, W.S. (1884) Investigations in Currency and Finance. Macmillan, London.

[2] Helphand, A. (Parvus) (1901) Die Sturm und Drang periode des Kapitals. In: Ernst, M., Ed., Die Handelskrisen und die Gewerkschaften. Edward Elga, Cheltenham.

[3] Van Gelderen, J. (1913) Springvloed: Beschouwingen over industriele ontwikkeling en prijsbeweging. De Nieuwe Tijd, 253, 269 and 445.

[4] De Wolff, S. (1924) Prosperitats-und Depressionsperioden. In: Jena, O.J., Ed., Der Lebendige Marxismus, Festgabe zum 70, Geburtstage von Karl Kautsky, 13-43.

[5] Kondratieff, N.D. and Oparin, D.I. (1928/1984) The "Long Wave Cycle" and "The Theses of N.D. Kondratieff's Paper: Long Cycles in Economic Conditions". In: Kondratieff, N. and Snyder, J.M., Eds., The Long Wave Cycle, Richardson \& Snyder, New York, 25-99, 101-105, 137-108.

[6] Kondratieff, N.D. and Oparin, D.I. (1928/1984) Long Economic Cycles. Richarson \& Snyder, New York.

[7] Kondratieff, N.D. (1935) The Long Waves in Economic Life. The Review of Economic Statistics, 17, 105-115. https://doi.org/10.2307/1928486

[8] Van Duijn, J. (1983) The Long Wave in Economic Life. George Allen \& Unwin Ltd., Shaftesbury, Dorset.

[9] Garvy, G. (1943) Kondratieff's Theory of Long Cycles. The Review of Economic Statistics, 25, 203-220. https://doi.org/10.2307/1927337

[10] Van der Zwan, A. (1980) On the Assessment of the Kondratieff Cycle and Related Issues. In: Kuipers, S.K. and Lanjouw, G.J., Eds., Prospects of Economic Growth, 
North-Holland Publishing Co., Amsterdam, 183-222.

[11] Van Ewijk, C. (1981) The Long Wave-A Real Phenomenon? De Economist, 129, 324-372. https://doi.org/10.1007/BF01371746

[12] Van Ewijk, C. (1982) A Spectral Analysis of the Kondratieff Cycle. Kyklos, 35, 468-499. https://doi.org/10.1111/j.1467-6435.1982.tb01226.x

[13] Solomou, S. (1990) Phases of Economic Growth, 1850-1973: Kondratieff Waves and Kuznets Swings. Cambridge University Press, Cambridge.

[14] Solomou, S. (1998) Economic Cycles: Long Cycles and Business Cycles since 1870. St. Martin's Press, New York.

[15] Kleinknecht, A. (1986) Long Waves, Depression and Innovation. De Economist, 134, 84-108. https://doi.org/10.1007/BF01705903

[16] Kleinknecht, A. and Bieshaar, H. (1984) Kondratieff Long Waves in Aggregate Output? An Econometric Test. Konjunkturpolitik, 30, 279-303.

[17] Korotayev, A. and Tsirel, S. (2010) A Spectral Analysis of World GDP Dynamics: Kondratieff Waves, Kuznets Swings, Juglar and Kitchin Cycles in Global Economic Development, and the 2008-2009 Economic Crisis. Structure and Dynamics, 4, 3-57.

[18] Reijnders, J.P.G. (1992) Between Trends and Trade Cycles: Kondratieff Long Waves Revisited. In: New Findings in Long Waves Research, St. Martin's Press, New York, 15-44. https://doi.org/10.1007/978-1-349-22450-0_2

[19] Reijnders, J.P.G. (2009) Trend Movements and Inverted Kondratieff Waves in the Dutch Economy, 1800-1913. Structural Change and Economic Dynamics, 20, 90-113. https://doi.org/10.1016/j.strueco.2009.03.003

[20] Van Duijn, J. (1977) The Long Wave in Economic Life. De Economist, 125, 544-576. https://doi.org/10.1007/BF01221051

[21] Metz, R. (1992) A Re-Examination of Long Waves in Aggregate Production Series. In: New Findings in Long-Wave Research, Palgrave Macmillan, 80-119. https://doi.org/10.1007/978-1-349-22450-0_4

[22] Metz, R. (2011) Do Kondratieff Waves Exist? How Time Series Techniques Can Help to Solve the Problem. Cliometrica, 5, 205-238. https://doi.org/10.1007/s11698-010-0057-9

[23] Mandel, E. (1975) "Long Waves" in the History of Capitalism (J. D. Bres, Trans.). In: Review, N.L., Ed., Late Capitalism, NLB, London, 108-146.

[24] Mandel, E. (1980) Long Waves of Capitalist Development: A Marxist Interpretation: Based on the Marshall Lectures Given at the University of Cambridge. Verso Books.

[25] Mandel, E. (1981) Explaining Long Waves of Capitalist Development 1. Futures, 13, 332-338. https://doi.org/10.1016/0016-3287(81)90148-8

[26] Gordon, D.M. (1980) Stages of Accumulation and Long Economic Cycles. In: H. T. K. and W. I., Eds., Processes of the World-System, Beverly Hills, 9-45.

[27] Gordon, D.M. (1991) Inside and Outside the Long Swing: The Endogeneity/Exogeneity Debate and the Social Structures of Accumulation Approach. Review (Fernand Braudel Center), 263-312.

[28] Gordon, D.M. (1994) Long Swings and Stages of Capitalism. In: Kotz, D.M. and McDonough, T., Eds., Social Structures of Accumulation: The Political Economy of Growth and Crisis, Cambridge University Press, 11-28. https://doi.org/10.1017/CBO9780511559501.002

[29] Gordon, D.M., Weisskopf, T.W. and Bowles, S. (1983) Long Swings and the Nonreproductive Cycle. The American Economic Review, 73, 152-157. 
[30] Kleinknecht, A. (1987) Innovation Patterns in Crisis and Prosperity: Schumpeter's Long Cycle Reconsidered. Macmillan, London.

[31] Mensch, G. (1975) Stalemate in Technology: Innovations Overcome the Depression. Ballinger, New York.

[32] Schumpeter, J.A. (1939) Business Cycles. A Theoretical, Historical and Statistical Analysis of the Capitalist Process. McGraw-Hill, New York.

[33] Kleinknecht, A. (1992) Long-Wave Research: New Results, New Departures-An Introduction. In: New Findings in Long-Wave Research, Palgrave Macmillan, 1-12. https://doi.org/10.1007/978-1-349-22450-0_1

[34] Clark, J., Freeman, C. and Soete, L. (1981) Long Waves, Inventions, and Innovations. Futures, 13, 308-322. https://doi.org/10.1016/0016-3287(81)90146-4

[35] Freeman, C. (1982) Innovation and Long-Cycles of Economic Development. Paper Presented at the Internacional Seminar on Innovation \& Development at the Industrial Sector.

[36] Perez, C. (1983) Structural Change and Assimilation of New Technologies in the Economic and Social Systems. Futures, 15, 357-375.

https://doi.org/10.1016/0016-3287(83)90050-2

[37] Perez, C. (1985) Microelectronics, Long Waves and World Structural Change: New Perspectives for Developing Countries. World Development, 13, 441-463. https://doi.org/10.1016/0305-750X(85)90140-8

[38] Perez, C. (2002) Technological Revolutions and Financial Capital: The Dynamics of Bubbles and Golden Ages. Edward Elgar Publishing. https://doi.org/10.4337/9781781005323

[39] Perez, C. (2004) Technological Revolutions, Paradigm Shifts and Socio-Institutional Change. In: Globalization, Economic Development and Inequality: An Alternative Perspective, Edward Elgar, Cheltenham, 217-242. https://doi.org/10.4337/9781845421625.00016

[40] Perez, C. (2010) Technological Revolutions and Techno-Economic Paradigms. Cambridge Journal of Economics, 34, 185. https://doi.org/10.1093/cje/bep051

[41] Tylecote, A. (1992) The Long Wave in the World Economy: The Present Crisis in Historical Perspective. Psychology Press.

[42] Rostow, W.W. (1975) Kondratieff, Schumpeter, and Kuznets: Trend Periods Revisited. The Journal of Economic History, 35, 719-753. https://doi.org/10.1017/S0022050700073745

[43] Volland, C.S. (1987) A Comprehensive Theory of Long Wave Cycles. Technological Forecasting and Social Change, 32, 123-145. https://doi.org/10.1016/0040-1625(87)90035-7

[44] Forrester, J.W. (1976) Business Structure, Economic Cycles, and National Policy. Futures, 8, 195-214. https://doi.org/10.1016/0016-3287(76)90106-3

[45] Sterman, J.D. (1985) A Behavioral Model of the Economic Long Wave. Journal of Economic Behavior \& Organization, 6, 17-53. https://doi.org/10.1016/0167-2681(85)90023-X

[46] Sterman, J.D. (1986) The Economic Long Wave: Theory and Evidence. System Dynamics Review, 2, 87-125. https://doi.org/10.1002/sdr.4260020202

[47] Minsky, H.P. (1992) The Financial Instability Hypothesis. The Jerome Levy Economics Institute Working Paper, No. 74.

[48] Romer, P.M. (1990) Endogenous Technological Change. Journal of Political Economy, 98, 71-102. https://doi.org/10.1086/261725 
[49] Aghion, P. and Howitt, P. (1990) A Model of Growth through Creative Destruction. No. w3223, National Bureau of Economic Research. https://doi.org/10.3386/w3223

[50] Helpman, E. and Trajtenberg, M. (1994) A Time to Sow and a Time to Reap: Growth Based on General Purpose Technologies. No. w4854, National Bureau of Economic Research. https://doi.org/10.3386/w4854

[51] Aghion, P. and Howitt, P. (1998) Endogenous Growth Theory. MIT Press.

[52] Kuhn, T.S. (1962) The Structure of Scientific Revolutions. 3rd Edition, University of Chicago Press, Chicago.

[53] Jovanovic, B. and Rob, R. (1990) Long Waves and Short Waves: Growth through Intensive and Extensive Search. Econometrica, 58, 1391-1409. https://doi.org/10.2307/2938321

[54] Olsson, O. (2000) Knowledge as a Set in Idea Space: An Epistemological View on Growth. Journal of Economic Growth, 5, 253-275. https://doi.org/10.1023/A:1009829601155

[55] Olsson, O. (2001) Why Does Technology Advance in Cycles? Working Papers in Economics.

[56] Olsson, O. (2005) Technological Opportunity and Growth. Journal of Economic Growth, 10, 31-53. https://doi.org/10.1007/s10887-005-1112-4

[57] Van Zon, A., Fortune, E. and Kronenberg, T. (2003) How to Sow and Reap as You Go: A Simple Model of Cyclical Endogenous Growth. MERIT Infonomics Research Memorandum Series, 2003-026.

[58] Yetkiner, I.H., de Vaal, A. and van Zon, A. (2003) The Cyclical Advancement of Drastic Technologies. FNU-21.

[59] Li, C.W. (2001) Science, Diminishing Returns and Long Waves. The Manchester School, 69, 553-573. https://doi.org/10.1111/1467-9957.00269

[60] Sanders, M. (2007) Scientific Paradigms, Entrepreneurial Opportunities and Cycles in Economic Growth. Small Business Economics, 28, 339-354. https://doi.org/10.1007/s11187-006-9038-6

[61] Jones, C.I. (1995) R \& D-Based Models of Economic Growth. Journal of Political Economy, 103, 759-784. https://doi.org/10.1086/262002

[62] Jones, C.I. (1998) Introduction to Economic Growth. W.W. Norton \& Company, London. 